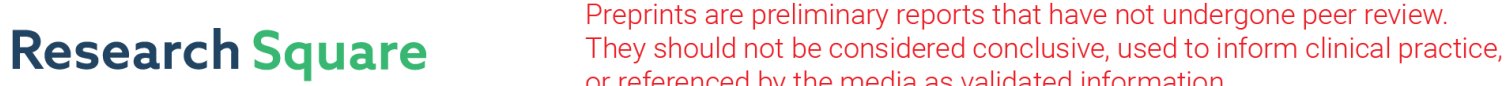 or referenced by the media as validated information. \\ Modeling and Simulation of Cancer Treatment Using Cold Atmospheric Plasma
}

Minghao Xu ( $\square$ albushom@gmail.com )

The Second Affiliated Hospital of Soochow University

\section{Research Article}

Keywords: CAP jet, cancer treatment, mathematic model

Posted Date: March 23rd, 2021

DOI: https://doi.org/10.21203/rs.3.rs-343877/v1

License: (c) (i) This work is licensed under a Creative Commons Attribution 4.0 International License. Read Full License 


\title{
Modeling and Simulation of Cancer Treatment Using Cold Atmospheric Plasma
}

\author{
Minghao $\mathrm{Xu}^{*}$ \\ *Department of Medical Oncology, The Second Affiliated Hospital of Soochow University, \\ Sanxiang Road 1055 Gusu District Suzhou, Jiangsu, China,
}

*Corresponding author: Minghao Xu

E-mail:albushom@gmail.com

\begin{abstract}
The cold atmospheric plasma (CAP) becomes a promising technology for the cancer cell treatment. There are many aspects affecting the effect of the treatment including plasma discharge voltages, CAP exposure time, cancer cell type and so on. In order to have a further understanding the cancer treatment using CAP jet, we proposed a mathematical model by using the least square method for the response of cancer cell line of U-87 MG with CAP jets treatment based on experimental data from reference. The comparison demonstrates that the mathematical model can capture the characteristics of the cancer cell viability in the experimental data. It means that we can use the same method to predict cancer cell response to CAP under a nominal condition. We also proposed the mathematic model using the Taylor expansion method according to the processed data to study the correlation between the cell viability, the treatment and the CAP exposure time.
\end{abstract}

Keywords: CAP jet; cancer treatment; mathematic model

\section{Background}

CAP jets as the non-equilibrium plasma, have been studied for many years and developed as a new promising therapeutic technology in cancer treatment $[1,2,3,4]$. As the CAP jets could just 
aim killing cancer cells without damaging the healthy ones $[5,6,7,8,9,10,11]$, it has been successfully used in lung carcinoma treatment, breast cancer treatment, head and neck carcinoma treatment, neuroblastoma treatment and so on $[12,13,14,15,16]$.

Kim et al applied the CAP jet for lung carcinoma treatment, demonstrating the effects of the CAP jet on the mouse lung carcinoma and fibroblast cells [17]. The CAP jet was applied in breast cancer treatment and the results showed that the CAP jets had a very sensitive effects on the breast cancer cells [18]. The plasma jet was investigated for the anti- cancer treatment, and the cell death effects of the CAP jet and its molecular mechanisms were studied using the $\mathrm{N}_{2}$ and air plasma jets, demonstrating the potential employment of the CAP jets in the cancer therapy. It is found that CAP jets can be used to generate the oxygen species to initiate the cancer cell apoptosis [19]. Graves et al presented a simulating model to analyze the thermal effects of the target using the CAP jet dynamics, showing the importance of the feedback control on the achieving spatially uniform dose delivery [20, 21].

Researchers found that there are many plasma parameters affecting the cancer treatment including the applied voltage, temperature, properties of the target, cancer types, and plasma composition, and so on $[12,13,15,16]$. What's more, it is found that the CAP exposure time has a crucial effect on the plasma characteristics and cancer cell viability [22].

In order to help further understanding the cancer treatment using CAP jet, we try to study the simulation method of the cancer treatment using CAP jets. In this paper, we processed the experimental data from reference [23], then proposed the mathematic model using the processed data to study the relation between the cell viability, CAP jets exposure time and the treatment time. We select the cell response of cancer cell line of U-87 MG under the CAP treatment. Firstly, we got the average viability according to the experimental data. Then use the least square method to get the coefficients of the mathematical model. Finally, we use the Taylor expansion method to get the polynomial of the cancer cell viability related to the CAP exposure duration and the CAP treatment time to predict the cancer cell viability under a nominal condition. 


\section{Results and Discussion}

Here we have processed the experimental data from [23] in Tables 1 to 5, which show the cell viability over 0 to $48 \mathrm{~h}$ under CAP exposure durations of $0 \mathrm{~s}, 30 \mathrm{~s}, 60 \mathrm{~s}, 90 \mathrm{~s}$, and $180 \mathrm{~s}$, respectively.

Table 1: Dynamic response of cancer viability for $\mathrm{U}-87$ with $\mathrm{U}=3.16 \mathrm{kV}$ and CAP exposure time $\Delta t=0 s$

\begin{tabular}{ccccc}
\hline & Experiment 1 & Experiment 2 & Experiment 3 & Experiment 4 \\
\hline $0 \mathrm{~h}$ & 0.9332 & 0.9332 & 0.9332 & 0.9332 \\
$0.4 \mathrm{~h}$ & 2.5668 & 2.5668 & 2.5668 & 2.5668 \\
$0.8 \mathrm{~h}$ & 4.0000 & 4.0000 & 4.0000 & 4.0000 \\
$1 \mathrm{~h}$ & 3.5763 & 3.7744 & 4.0126 & 3.8137 \\
$6 \mathrm{~h}$ & 4.4705 & 4.4705 & 5.0372 & 5.1706 \\
$12 \mathrm{~h}$ & 5.0414 & 5.6080 & 5.3080 & 5.3414 \\
$24 \mathrm{~h}$ & 5.6825 & 5.8159 & 5.4826 & 6.1492 \\
$48 \mathrm{~h}$ & 5.7986 & 6.2986 & 6.1652 & 6.1986 \\
\hline
\end{tabular}

Table 2: Dynamic response of cancer viability for $\mathrm{U}-87$ with $\mathrm{U}=3.16 \mathrm{kV}$ and CAP exposure time $\Delta t=30 s$

\begin{tabular}{ccccc}
\hline & Experiment 1 & Experiment 2 & Experiment 3 & Experiment 4 \\
\hline $0 \mathrm{~h}$ & 0.4667 & 0.8167 & 0.5444 & 0.35 \\
$0.4 \mathrm{~h}$ & 2.0220 & 2.2165 & 2.3720 & 2.4108 \\
$0.8 \mathrm{~h}$ & 3.6548 & 4.0826 & 3.9660 & 3.8104 \\
$1 \mathrm{~h}$ & 3.7325 & 3.9658 & 3.7710 & 4.2380 \\
$6 \mathrm{~h}$ & 4.7784 & 4.7008 & 5.1674 & 4.8174 \\
$12 \mathrm{~h}$ & 5.0463 & 5.4352 & 5.2796 & 5.2019 \\
$24 \mathrm{~h}$ & 5.3870 & 5.8925 & 5.5814 & 6.5925 \\
$48 \mathrm{~h}$ & 6.0681 & 6.0292 & 5.7959 & 6.6125
\end{tabular}

Table 3: Dynamic response of cancer viability for $\mathrm{U}-87$ with $\mathrm{U}=3.16 \mathrm{kV}$ and CAP exposure time $\Delta t=60 \mathrm{~s}$ 


\begin{tabular}{c|cccc}
\hline & Experiment 1 & Experiment 2 & Experiment 3 & Experiment 4 \\
\hline $0 \mathrm{~h}$ & 0.2333 & 0.4 & 0.2 & 0.3334 \\
$0.4 \mathrm{~h}$ & 1.8667 & 1.7997 & 1.8333 & 1.7660 \\
$0.8 \mathrm{~h}$ & 3.2662 & 3.6325 & 3.2661 & 3.1328 \\
$1 \mathrm{~h}$ & 3.7327 & 3.9327 & 3.8993 & 3.9912 \\
$6 \mathrm{~h}$ & 4.0960 & 4.2628 & 4.5626 & 4.5626 \\
$12 \mathrm{~h}$ & 4.7919 & 5.0586 & 4.9586 & 5.2252 \\
$24 \mathrm{~h}$ & 5.3172 & 5.9172 & 4.6172 & 5.1839 \\
$48 \mathrm{~h}$ & 3.2013 & 4.3016 & 3.1346 & 3.8346 \\
\hline
\end{tabular}

Table 4: Dynamic response of cancer viability for $\mathrm{U}-87$ with $\mathrm{U}=3.16 \mathrm{kV}$ and CAP exposure time $\Delta t=90 \mathrm{~s}$

\begin{tabular}{ccccc}
\hline & 1 & 2 & 3 & 4 \\
\hline $0 \mathrm{~h}$ & 0.1955 & 0.19553 & 0.1995 & 0.2513 \\
$0.4 \mathrm{~h}$ & 1.5083 & 1.4245 & 1.6480 & 1.3687 \\
$0.8 \mathrm{~h}$ & 3.4916 & 3.5474 & 3.2681 & 3.1005 \\
$1 \mathrm{~h}$ & 3.9324 & 3.8826 & 3.5195 & 3.8796 \\
$6 \mathrm{~h}$ & 4.1894 & 4.4972 & 4.6089 & 4.5251 \\
$12 \mathrm{~h}$ & 3.0726 & 2.9608 & 2.9888 & 2.7653 \\
$24 \mathrm{~h}$ & 2.6536 & 2.8212 & 2.5139 & 2.5698 \\
$48 \mathrm{~h}$ & 2.4581 & 2.5698 & 2.4022 & 2.2905 \\
\hline
\end{tabular}

Table 5: Dynamic response of cancer viability for $\mathrm{U}-87$ with $\mathrm{U}=3.16 \mathrm{kV}$ and CAP exposure time $\Delta t=180 \mathrm{~s}$

\begin{tabular}{ccccc}
\hline & 1 & 2 & 3 & 4 \\
\hline $0 \mathrm{~h}$ & 0.3351 & 0.3575 & 0.2011 & 0.2011 \\
$0.4 \mathrm{~h}$ & 1.0502 & 0.8938 & 1.2960 & 1.1173 \\
$0.8 \mathrm{~h}$ & 1.9888 & 1.7653 & 2.0782 & 1.9217 \\
$1 \mathrm{~h}$ & 2.7932 & 2.5698 & 2.6815 & 2.4581 \\
$6 \mathrm{~h}$ & 3.7318 & 3.8882 & 3.1955 & 3.0614 \\
$12 \mathrm{~h}$ & 1.7877 & 1.8994 & 1.4301 & 1.2067 \\
$24 \mathrm{~h}$ & 1.4078 & 1.4748 & 1.2201 & 1.1843
\end{tabular}




$\begin{array}{lllll}48 \mathrm{~h} & 1.2737 & 1.3184 & 1.1620 & 0.9385\end{array}$

In order to investigate the cancer cell viability with time, we formulate a mathematical expression to cancer cell viability at different CAP exposure durations. Firstly, we got the average viability according to the tables 1 to 5, which is shown in Table 6 .

Table 6: The Dynamic response of cancer viability for $\mathrm{U}-87$ with $\mathrm{U}=3.16 \mathrm{kV}$ with different CAP exposure times

\begin{tabular}{cccccl}
\hline & $\Delta t=0 s$ & $\Delta t=30 s$ & $\Delta t=60 s$ & $\Delta t=90 s$ & $\Delta t=180 s$ \\
\hline $0 \mathrm{~h}$ & 0.9332 & 0.5444 & 0.2916 & 0.2094 & 0.2737 \\
$0.4 \mathrm{~h}$ & 2.5668 & 2.2553 & 1.8164 & 1.4874 & 1.0893 \\
$0.8 \mathrm{~h}$ & 4.0000 & 3.8784 & 3.3244 & 3.3519 & 1.9385 \\
$1 \mathrm{~h}$ & 3.7942 & 3.9268 & 3.8889 & 3.8035 & 2.6256 \\
$6 \mathrm{~h}$ & 4.7872 & 4.8660 & 4.3710 & 4.4552 & 3.4692 \\
$12 \mathrm{~h}$ & 5.3247 & 5.2407 & 5.0086 & 2.9468 & 1.5809 \\
$24 \mathrm{~h}$ & 5.7825 & 5.8633 & 5.2588 & 2.6396 & 1.3217 \\
$48 \mathrm{~h}$ & 6.1152 & 6.1264 & 3.6180 & 2.4302 & 1.1732 \\
\hline
\end{tabular}

Based on the experimental results, we proposed an expression for the net proliferation rate $p$. (1)

$$
p(\mathrm{t})=\left(\mathrm{a}_{1}+a_{2} \mathrm{t}+a_{3} \mathrm{t}^{2}\right) \exp \left(-a_{4}^{-t}\right) /\left(\mathrm{a}_{5} \mathrm{t}^{2}+a_{6}\right)
$$

Where $a_{1}, a_{2}, a_{3}, a_{4}, a_{5}, a_{6}$ are the coefficients to be determined for each CAP exposure time by the data in Table 6. We use the least squares method to process the discrepancy between the mathematical model and data in Table 6 to get function expression for each exposure time. That means the coefficients of $a_{1}, a_{2}, a_{3}, a_{4}, a_{5}, a_{6}$ were got by solving the following objective function.

$$
J=\min \sum_{i=1}^{n} \int_{0}^{48}\left\|p_{e}(t)-p(t)\right\|^{2} d t
$$

Combine Eq. (1) and (2), we obtain the coefficients of $a_{1}, a_{2}, a_{3}, a_{4}, a_{5}, a_{6}$ for each expression of cancer cell viability with CAP exposure time of 0 s, 30 s, 60 s, 90 s, and 180 s, which can be seen in the following Table 7. 
Table 7: The coefficients for the expression of cancer viability for $\mathrm{U}-87$ with $\mathrm{U}=3.16 \mathrm{kV}$ of different CAP exposure times

\begin{tabular}{lllllll}
\hline$\Delta t$ & $\mathrm{C}_{1}$ & $\mathrm{C}_{2}$ & $\mathrm{C}_{3}$ & $\mathrm{C}_{4}$ & $\mathrm{C}_{5}$ & $\mathrm{C}_{6}$ \\
\hline $0 \mathrm{~s}$ & $-2.138 \times 10^{-6}$ & $-5.373 \times 10^{-6}$ & $-7.353 \times 10^{-6}$ & 1.224 & $-1.267 \times 10^{-6}$ & $-5.723 \times 10^{-7}$ \\
$30 \mathrm{~s}$ & 8.127 & -35.13 & 180.6 & 165.6 & 32.24 & 4.413 \\
$60 \mathrm{~s}$ & 10.73 & 34.72 & 60.49 & 58.22 & 13.73 & 13.35 \\
$90 \mathrm{~s}$ & 24.58 & 340.5 & 43.29 & 2.785 & 21.88 & 51.23 \\
$180 \mathrm{~s}$ & $6.027 \times 10^{-6}$ & $4.107 \times 10^{-5}$ & $1.281 \times 10^{-6}$ & 2.466 & $2.262 \times 10^{-6}$ & $1.033 \times 10^{-5}$ \\
\hline
\end{tabular}

Figures 1 shows the comparison of the mathematical simulation results and the experimental data for U-87 MG with applied voltage of $3.16 \mathrm{kV}$ at different CAP exposure time of $0 \mathrm{~s}, 30 \mathrm{~s}, 60 \mathrm{~s}, 90$ s, and $180 \mathrm{~s}$, respectively. It demonstrates that the mathematical model in this paper captures the experimental data successfully.

Figure 2 shows the dynamics response of cancer cell viability of the mathematical simulation model with plasma voltage of $3.16 \mathrm{kV}$ for cancer cell of U-87 MG. From figure 2, we can get the cancer cell viability at any time for the five CAP exposure time with the voltage of $3.16 \mathrm{kV}$.

We can conclude from figure 1 and figure 2 that the mathematical model can be used to predict the cancer cell viability under any CAP treatment conditions. We can just combine the formula (1) and formula (2) and calculate the coefficients using the least square method.

In order to have a better understanding of the response of cancer cell viability of U-87 MG for arbitrary CAP exposure duration, we also investigate the correlation of the cancer cell viability with the CAP exposure time and the treatment time.

Then, we use the Taylor expansion method to get the polynomial of the cancer cell viability related to the CAP exposure duration and the CAP treatment in the following expression (3).

$$
p(\Delta t, t)=a_{0}+a_{1} \Delta t+a_{2}(\Delta t)^{2}+a_{3} \Delta t \cdot t+a_{4} t^{2}
$$

According to the data in Table 6, we obtain the coefficients 


$$
a_{0}=2.229, \quad a_{1}=0.02233, \quad a_{2}=0.56, \quad a_{3}=-0.0005, \quad a_{4}=-0.002
$$

Figure 3 shows the response of the cancer cell viability from generalized mathematical model (3) for arbitrary CAP treatment duration $\Delta \mathrm{t}$ and time $\mathrm{t}$. We can use formula (2) to predict the cancer cell viability for arbitrary CAP treatment duration $\Delta \mathrm{t}$ and time $\mathrm{t}$. For example, $\Delta t=25 \mathrm{~s}, \mathrm{t}=3 \mathrm{~h}$, the cancer cell viability could be around 3.52 .

\section{Conclusions}

CAP is a promising technology in the cancer cell treatment. The cancer cell viability under the CAP treatment is influenced by plasma discharge voltages, CAP exposure time, gas composition, cancer cell type and so on. In this paper, we proposed the mathematical simulation model to predict the cancer cell viability under arbitrary CAP exposure time and treatment time.

(1) We use the average cancer cell viability and the least square method to solve the coefficients of the proposed mathematical model. Then we compare the response of the cancer cell viability from the mathematical model and the experimental data, it is found that the mathematical model can capture the characteristics of the response successfully. It means that we can use the same method to predict cancer cell response to CAP under a nominal condition.

(2) We also proposed the mathematic model using the Taylor expansion method using the average data to study the correlation between the cell viability, CAP exposure time and the treatment time. We can use it to predict the cancer cell viability for arbitrary CAP treatment duration $\Delta \mathrm{t}$ and time $\mathrm{t}$. That is to say the cancer cell viability can be predict using the same method to under any CAP treatment conditions.

\section{Material and Method}

We proposed the mathematic model using the experimental data in Ref [23]. We select the experimental data of cancer cell line of U-87 MG under the CAP treatment. The CAP exposure duration is from $0 \mathrm{~s}$ to $180 \mathrm{~s}$ and the applied voltage is $3.16 \mathrm{kV}$. We proposed the mathematical model to study the relation between the cell viability, CAP jet exposure time and the treatment 
time.

\section{Declarations}

\section{Ethics approval and consent to participate}

Not applicable

\section{Consent for publication}

Not applicable

\section{Availability of data and materials}

All data generated or analyzed during this study are included in this article.

\section{Competing interests}

The authors declare that they have no competing interests

\section{Funding}

Not applicable

\section{Authors' contributions}

Minghao $\mathrm{Xu}$ is the sole author of the article.

\section{Acknowledgements}

Not applicable

\section{References}

1. Keidar M, Yan D, Beilis Ii, Trink B, Sherman JH. Plasmas for treating cancer: opportunities for adaptive and self-adaptive approaches. Trends Biotechnol. 2018;36:586-93.

2. Stoffels, E, Kieft, IE, Sladek, REJ, Van Den Bedem LJM, Laan EPVD, Steinbuch M. Plasma needle for in vivo medical treatment: recent developments and perspectives. Plasma Sources Sci. Technol. 2006;15:S169.

3. Li L, Michael K. Cold atmospheric plasma jet in an axial DC electric field. Phys Plasmas. 2016;23:083529

4. Weltman KD, Von Woedtke T. Plasma medicine-current state of research and medical application. Plasma Phys Control Fusion. 2017;59:014031. 
5. Knake N, Niemi K, Reuter S, Schulz-Von Der Gathen V, Winter J. Absolute atomic oxygen density profiles in the discharge core of a microscale atmospheric pressure plasma jet. Appl Phys Lett. 2008;93:131503.

6. Waskoenig J, Niemi K, Knake N, Graham LM, Reuter S, Schulz-Von Der Gathen V, Gans T. Atomic oxygen formation in a radio-frequency driven micro-atmospheric pressure plasma jet. Plasma Sources Sci T. 2010;19:045018.

7. Keidar M. Plasma for cancer treatment. Plasma Sources Sci T. 2015;24:033001.

8. Arndt S, Wacker E, Li YF, Shimizu T, Thomas HM, Morfill GE, Karrer S, Zimmermann JL, Bosserhoff AK. Cold atmospheric plasma, a new strategy to induce senescence in melanoma cells. Exp Dermatol. 2013;22:284-289.

9. Conway G, Casey A, Milosavljevic V, Liu Y, Howe O, Cullen PJ, Curtin JF. Non-thermal atmospheric plasma induces ROS-independent cell death in U373MG glioma cells and augments the cytotoxicity of temozolomide. Brit J Cancer. 2016;114:435-43.

10. Schlegel J, Köritzer J, Boxhammer V. Plasma in cancer treatment. Clinical Plasma Medicine. 2013;1:2-7.

11. Vandamme M, Robert E, Lerondel S, Sarron V, Ries D, Dozias S, Sobilo J, Gosset D, Kieda C, Legrain B, Pouvesle Jm. Ros implication in a new antitumor strategy based on non-thermal plasma. Int J Cancer. 2012;130:2185-94.

12. Darny T, Pouvesle Jm, Puech V, Douat C, Dozias S, Robert E. Analysis of conductive target influence in plasma jet experiments through helium metastable and electric field measurements. Plasma Sources Sci T. 2017;26:045008.

13. Klarenaar B1, Guaitella O, Engeln R, Sobota A. How dielectric, metallic and liquid targets influence the evolution of electron properties in a pulsed He jet measured by Thomson and Raman scattering. Plasma Sources Sci T. 2018;27:085004.

14. Dezest M, Chavatte L, Bourdens M, Quinton D, Camus M, Garrigues L, Descargues P, Arbault S, Burlet-Schiltz O, Casteilla L, Clément F. Mechanistic insights into the impact of 
cold atmospheric pressure plasma on human epithelial cell lines. Sci Rep. 2017;7:1-7.

15. Keidar M. A prospectus on innovations in the plasma treatment of cancer. Phys Plasmas. 2018;25:083504.

16. Darny T, Pouvesle Jm, Puech V, Douat C, Dozias S, Robert E. Analysis of conductive target influence in plasma jet experiments through helium metastable and electric field measurements. Plasma Sources Sci T. 2017;26:045008.

17. Kim JY, Ballato J, Foy P, Hawkins T, Wei Y, Li J, Kim So. Apoptosis of lung carcinoma cells induced by a flexible optical fiber-based cold microplasma. Biosens Bioelectron. $2011 ; 28: 333-8$.

18. Wang M, Holmes B, Cheng X, Zhu W, Keidar M, Zhang Lg. Cold atmospheric plasma for selectively ablating metastatic breast cancer cells. PloS one. 2013;8:e73741.

19. Ahn Hj, Kim Ki, Kim G, Moon E, Yang Ss, Lee Js. Atmospheric-pressure plasma jet induces apoptosis involving mitochondria via generation of free radicals. PloS one. 2011;6:e28154.

20. Gidon D, Graves DB, Mesbah A. Spatial thermal dose delivery in atmospheric pressure plasma jets. Plasma Sources Sci T. 2019;28:025006.

21. Gidon D, Graves DB, Mesbah A. Effective dose delivery in atmospheric pressure plasma jets for plasma medicine: a model predictive control approach. Plasma Sources Sci T. 2017;26:085005.

22. Georgescu N, Lupu AR. Tumoral and normal cells treatment with high-voltage pulsed cold atmospheric plasma jets. IEEE T Plasma Sci. 2010;38:1949-55.

23. Gjika E, Pal-Ghosh S, Tang A, Kirschner M, Tadvalkar G, Canady J, Stepp Ma, Keidar M. Adaptation of operational parameters of cold atmospheric plasma for in vitro treatment of cancer cells. Acs Appl Mater Inter. 2018;10:9269-79. 


\section{Figure legend}

Figure 1: Comparison of the mathematical simulation results of cell viability with experimental data for U-87 MG with the applied voltage of $3.16 \mathrm{kV}$ at different CAP exposure time of (a) $\Delta t=$ $0 s$, (b) $\Delta t=30 s$, (c) $\Delta t=60 s$, (d) $\Delta t=90 s$, and (e) $\Delta t=180 \mathrm{~s}$

Figure 2: The mathematical simulation model with plasma voltage of $3.16 \mathrm{kV}$ for cancer cell of U-87 MG.

Figure 3: Response of cell viability from generalized mathematical model (3) for arbitrary CAP treatment duration $\Delta \mathrm{t}$ and time $\mathrm{t}$. 

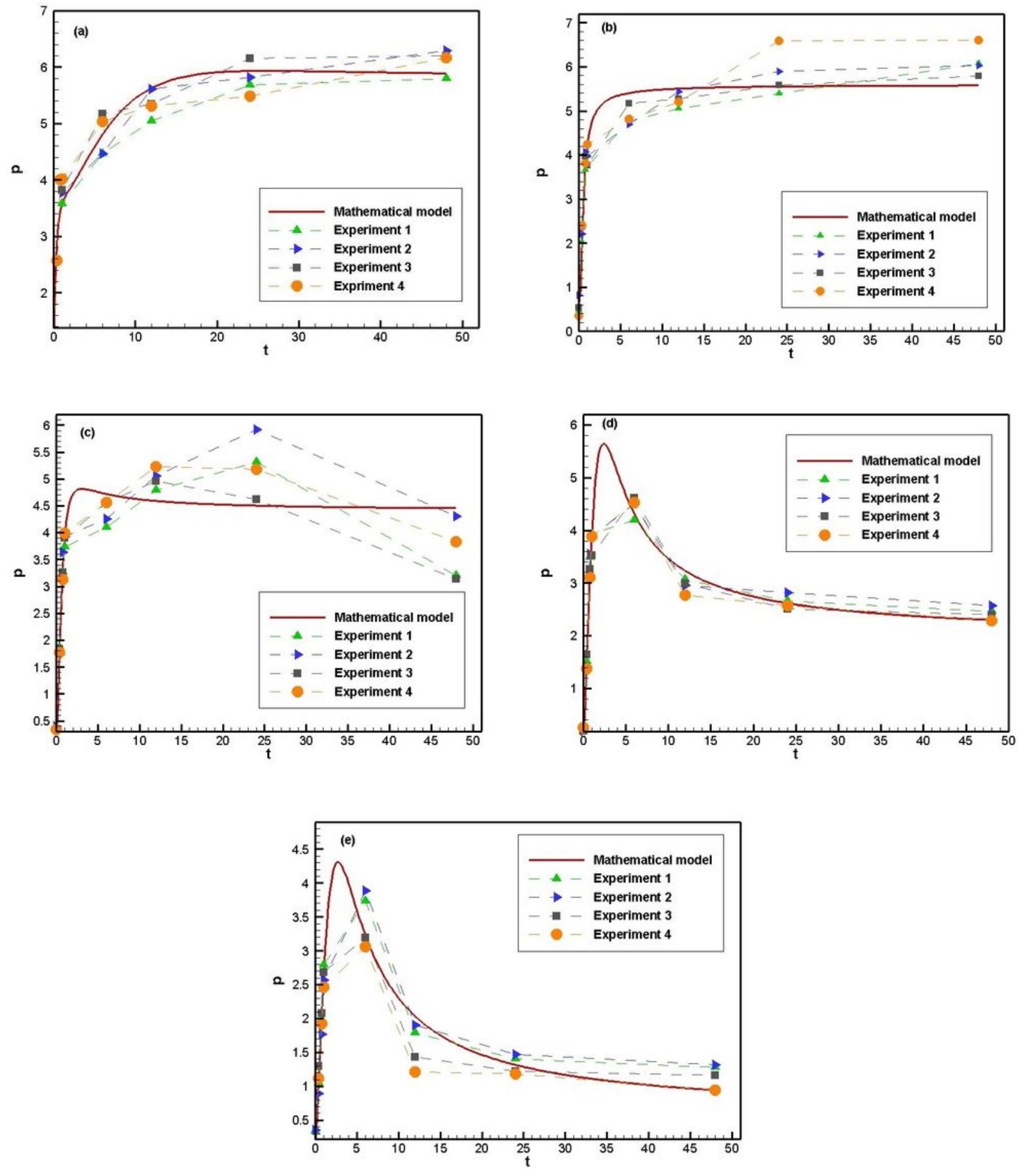

Figure 1

Comparison of the mathematical simulation results of cell viability with experimental data for U-87 MG with the applied voltage of $3.16 \mathrm{kV}$ at different CAP exposure time of (a) $\Delta \mathrm{t}=0 \mathrm{~s}$, (b) $\Delta \mathrm{t}=30 \mathrm{~s}$, (c) $\Delta \mathrm{t}=60 \mathrm{~s}$, (d) $\Delta \mathrm{t}=90 \mathrm{~s}$, and (e) $\Delta \mathrm{t}=180 \mathrm{~s}$ 


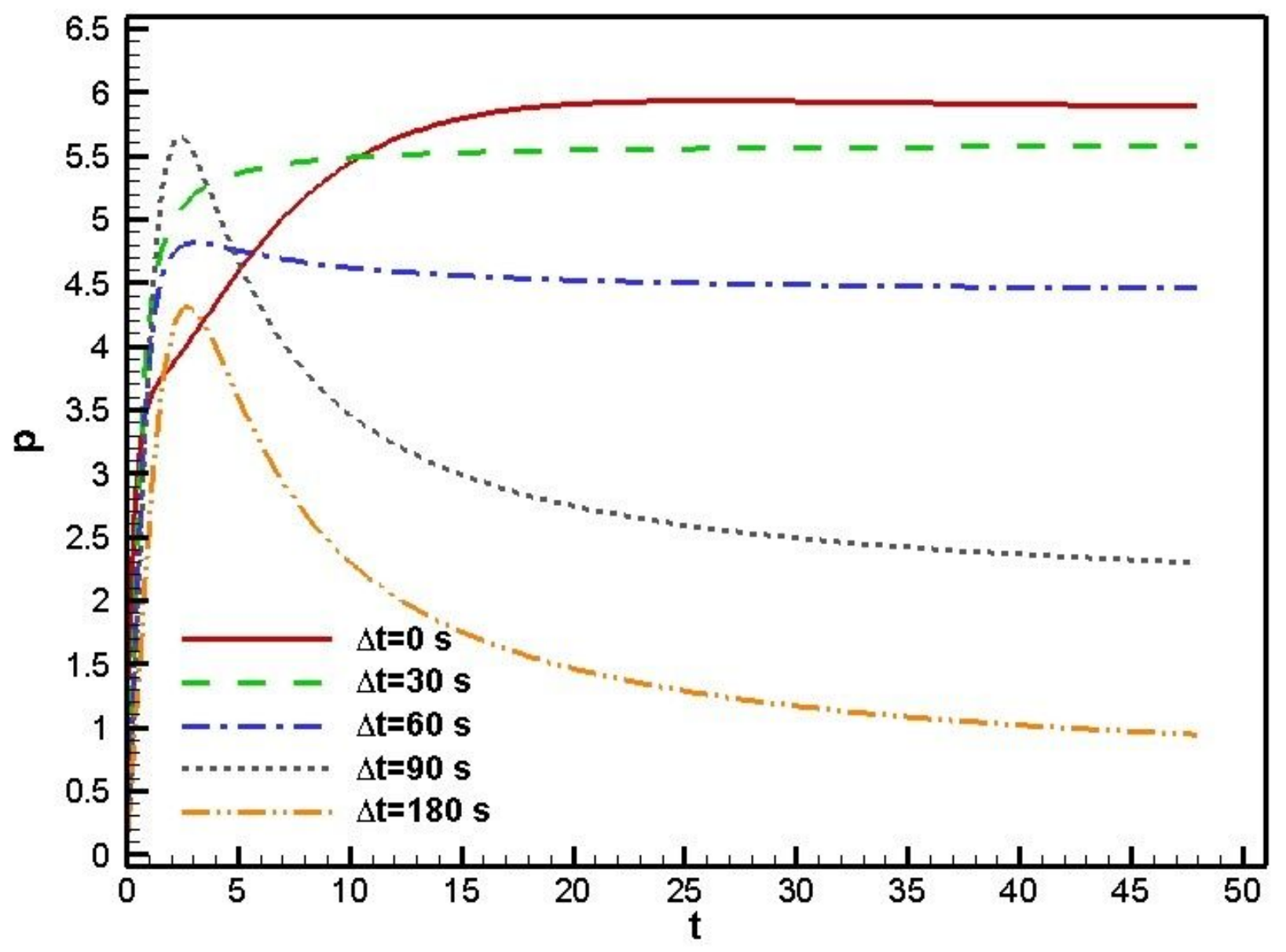

Figure 2

The mathematical simulation model with plasma voltage of $3.16 \mathrm{kV}$ for cancer cell of U-87 MG. 


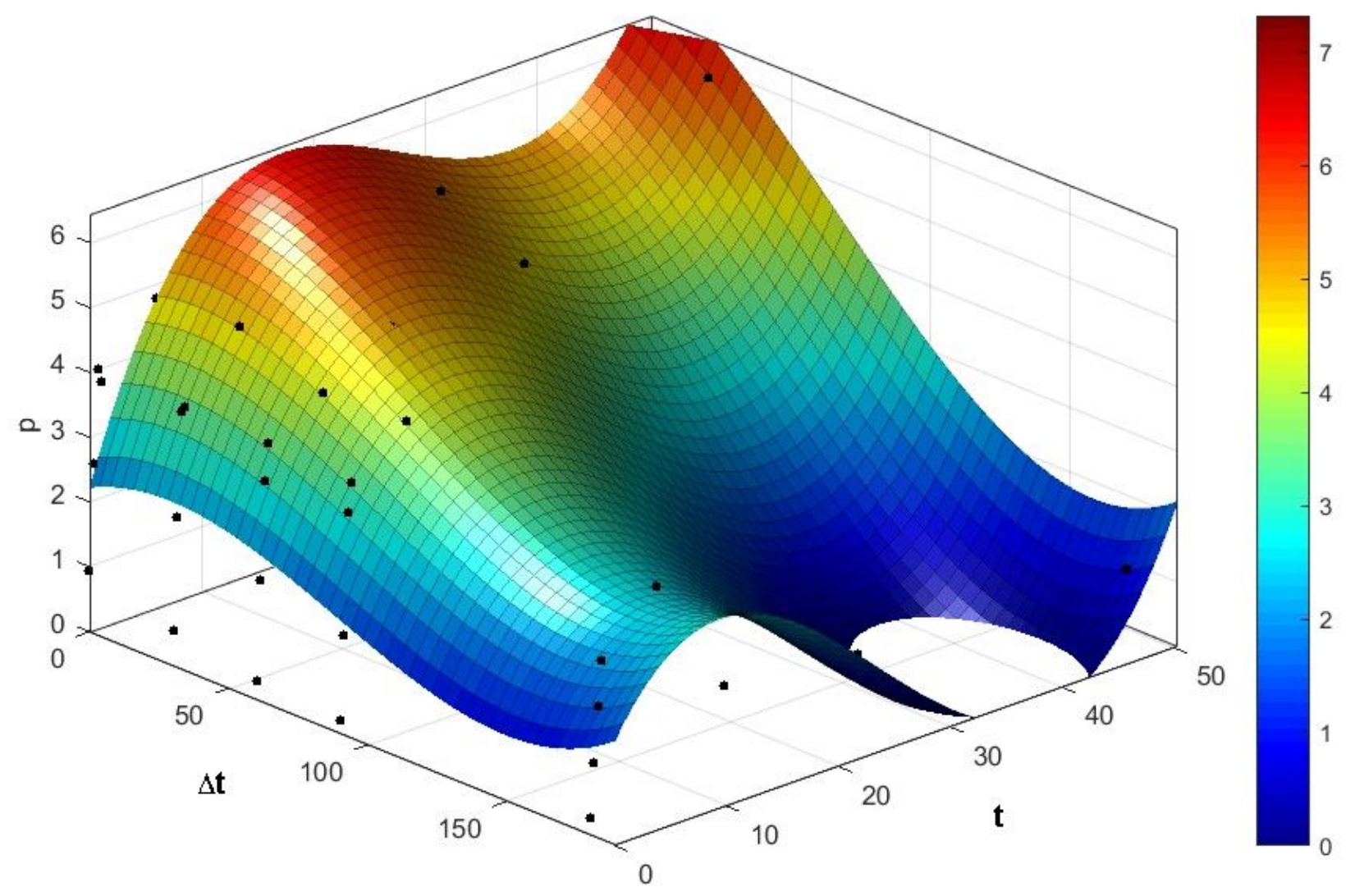

Figure 3

Response of cell viability from generalized mathematical model (3) for arbitrary CAP treatment duration $\Delta \mathrm{t}$ and time t. 